\title{
EFFECT OF SIMULATING TOOTH BRUSHING ON SURFACE CHANGE OF DIFFERENT CERAMIC MATERIALS
}

\author{
Khaled Haggag*, Muhammad Abbas ${ }^{* *}$, Hussein Ramadan*** and Mohamed Fawzy ${ }^{* * *}$
}

\begin{abstract}
Objectives: Purpose of the present study was to evaluate the surface roughness of current ceramics before and after tooth brushing abrasion, using simulated tooth brushing wear testing.

Materials and Methods: 40 ceramic samples (Zirconia ceramics, Vita Enamic, Lava Ultimate, \& E-max ceramics) were cut from corresponding 4 types of ceramic blocks using microtome, then 40 samples were divided into 4 groups $(n=10)$. Each sample has a fixed dimension about $10 \times 10 \times 2 \mathrm{~mm}$ (thickness). The 3-body simulated tooth brushing wear testing was performed using a programmable logic controlled equipment; ROBOTA chewing simulator* integrated with thermo-cyclic protocol, then Surface roughness of each material ( $\mathrm{Ra}$ ) was measured with USB digital surface profile gauge.
\end{abstract}

Results: Total effect of material; regardless to toothbrush wear simulation cycles, totally there was no-significant $(\mathrm{p}=0.1379>0.05)$ difference between all materials where $(\mathrm{Zr} \geq$ e.max $\geq \mathrm{V}$ enamic $\geq \mathrm{L}$ ultimate) with their mean values respectively after 24 months $(\mathrm{Zr}$; $0.25898 \pm 0.0035$, e.max; $0.25428 \pm 0.0029$, V enamic; $0.25413 \pm 0.0049$, L ultimate; $0.25403 \pm 0.0028$ ). Total effect of toothbrush wear simulation cycles; irrespective of material, totally toothbrush wear simulation cycles did not affect roughness significantly $(\mathrm{p}=0.8281>0.05)$ difference between all materials where ( $18 \mathrm{~m} \geq$ baseline $\geq 6 \mathrm{~m} \geq 24 \mathrm{~m} \geq 12 \mathrm{~m}$ ).

Conclusions: Brushing of ceramic materials with conventional dentifrices non-significantly increased surface roughness, where results of surface roughness present within the clinically acceptable range, not insult the patient intraorally.

\section{INTRODUCTION}

Tooth brushing using different types of tooth pastes is considered the most popular habit carried out by many individuals for improvement of their oral hygiene in several countries. Regardless of different types of brushes either power operated (include: battery-operated oscillating, rechargeable sonic effect brushes, or rechargeable operated oscillating brushes) or manually operated brushes

\footnotetext{
* Assistant Professor, Crown and Bridge Department, Faculty of Dental Medicine, Al Azhar University, Egypt ** Assistant Professor, Dental Biomaterials Department, Faculty of Dental medicine, Al-Azhar University, Egypt *** Lecturer, Crown and Bridge Department, Faculty of Dental Medicine, Al Azhar University, Egypt
} 
have positive effect on stain removal and plaque removal. ${ }^{(1-3)}$ This cleaning effect of regular tooth brushing may be attributed in different studies to the mechanical effect of the brush itself as well as the mechanical/chemical traits or criteria of tooth paste. ${ }^{(4,5)}$ Regardless of these advantages of tooth brushing, negative effect of brushing such as dental hypersensitivity and tooth surface erosion and surface wear of some dental restorations may result. ${ }^{(6-8)}$

Various all ceramic fixed dental prostheses (metal-free restorations) have introduced in dental market and commonly used nowadays to ameliorate appearance or aesthetic. ${ }^{(9-11)}$ These materials are extremely several in the clinical employment either in coping and monolithic form, microstructure (polycrystalline ceramics, predominantly glassbased ceramics, resin-based ceramics) and manufacturing technique. ${ }^{(10,12,13)}$

Ceramic fixed dental prostheses might suffer from surface roughness after extended usage in patient's mouth, although their higher mechanical properties and their higher resistance to wear in oral environment, ${ }^{(14)}$ but sometimes the brushing action might affect surface roughness and jeopardize the aesthetic of these restorations.

Yttrium-stabilized tetragonal zirconia polycrystals (Y-TZP) is one of recently used ceramic materials, it is characterized by its higher resistance to alkalis and acids, good biocompatible material, good wear resistance and mechanical properties. ${ }^{(14,15)}$ Furthermore, new hybrid ceramic materials (resinbased ceramic, resin-nano ceramics and polymer infiltrated ceramic) have been introduced into dental market and available nowadays for CAD/CAM technology. It combines the mechanical properties of both polymers and ceramics. ${ }^{(16,17)}$

Until now, there are inadequate researches and few studies examining and interesting with wear behavior of different ceramic restorations such as veneered zirconia, full contoured zirconia, and hybrid ceramics, ${ }^{(8-20)}$ moreover there are also insufficient researches and studies concerning with effect of tooth brushing on a surface change of different cemented ceramic restorations.

Purpose of the present study was to evaluate the surface roughness of current ceramics before and after toothbrush abrasion. The null hypothesis was that tooth brushing does not affect the surface roughness and wear of dental restorations.

\section{MATERIALS AND METHODS}

40 ceramic samples (Zirconia ceramics, Vita Enamic, Lava Ultimate, \& E-max ceramics) were cut from corresponding 4 types of ceramic blocks using micro saw (Isomat 4000 micro saw, Buehler, USA), then 40 samples were divided into 4 groups $(n=10)$. Each sample has a fixed dimension about $10 \times 10 \times$ ( $2 \mathrm{~mm}$ thickness $)$.

TABLE (1) Materials used in the study names, types and manufacturers

\begin{tabular}{|c|c|c|}
\hline Brand & Material type & Manufacturer \\
\hline Prettau & $\begin{array}{c}\text { Translucent } \\
\text { monolithic zirconia }\end{array}$ & $\begin{array}{c}\text { Zirkonzahn, Taufers, } \\
\text { Italy }\end{array}$ \\
\hline $\begin{array}{c}\text { IPS E-max } \\
\text { CAD }\end{array}$ & $\begin{array}{c}\text { Lithium Disilicate } \\
\text { ceramics }\end{array}$ & $\begin{array}{c}\text { Ivoclar, Liechtenstein, } \\
\text { Germany }\end{array}$ \\
\hline Vita \\
Enamic & $\begin{array}{c}\text { Glass ceramic in a } \\
\text { resin interpenetrating } \\
\text { matrix }\end{array}$ & $\begin{array}{c}\text { Vita, VITA } \\
\text { Zahnfabrik, Germany }\end{array}$ \\
\hline $\begin{array}{c}\text { Lava } \\
\text { Ultimate }\end{array}$ & Resin nano-ceramic & $\begin{array}{l}\text { 3M EPSE, N525442 } \\
\text { Deutschland, } \\
\text { Germany }\end{array}$ \\
\hline
\end{tabular}

\section{Tooth brush wear simulation test}

The 3-body simulated tooth brushing wear testing was performed using a programmable logic controlled equipment; the newly developed four chambers multimodal Dual-axis ROBOTA chewing simulator* integrated with thermo-cyclic protocol operated on servo-motor (Model ACH-09075DC-T, AD-Tech Technology Co., Ltd., Germany) (fig.1A). 
The device allows simulation of the vertical and horizontal movements simultaneously. Each of the chambers consists of an upper Jackob's chuck as tooth brush antagonist holder that can be tightened with a screw and a lower plastic sample holder in which the sample can be embedded (fig. 1 B1). The ceramic samples were embedded in Teflon housing in the lower sample holder (fig. 1 B2). A weight of $300 \mathrm{~g}$, which is comparable to $3 \mathrm{~N}$ of brushing force was exerted according to previous studies ${ }^{(21)}$ (table: 1).

TABLE (2) Wear test parameters used in the study

\begin{tabular}{|c|c|}
\hline Vertical movement: $1 \mathrm{~mm}$ & Horizontal movement: $3 \mathrm{~mm}$ \\
\hline Rising speed: $90 \mathrm{~mm} / \mathrm{s}$ & Forward speed: $90 \mathrm{~mm} / \mathrm{s}$ \\
\hline Descending speed: $40 \mathrm{~mm} / \mathrm{s}$ & \begin{tabular}{c} 
Backward speed: $40 \mathrm{~mm} / \mathrm{s}$ \\
\hline Cycle frequency $1.6 \mathrm{~Hz}$
\end{tabular} \\
$\begin{array}{c}\text { Weight per sample: from } \\
300 \mathrm{~g}\end{array}$ \\
\hline Torque; $2.4 \mathrm{~N} . \mathrm{m}$ & \\
\hline
\end{tabular}

Simulated tooth brushing was performed using toothbrush heads with soft nylon bristles (Oral B Indicator; Procter \& Gamble Nanning, Kwangsi, China) under 300-gr load. The toothbrush heads were changed after every 5,000 strokes. For each sample, 20,000 strokes were performed at a frequency of 180 strokes/min. A double pass of the toothbrush head was considered a stroke. Assuming that 10,000 cycles represented approximately 1 year of tooth brushing, ${ }^{(22)}$ the cycles were divided into different aging simulations of 6 months $(5,000$ strokes); 12 months (10000 strokes), 18 months (15000 strokes) and 24 months (20000 strokes).

\section{Abrasive medium;}

Slurry was prepared by mixing a $2: 1$ ratio of deionized water and a sodium fluoride $0.22 \% \mathrm{w} / \mathrm{w}$ (1000 ppm F) particle dentifrice (Colgate maxfresh; Colgate-Palmolive, Bangna-Trad, Amphur Muang, Chonburi, Thailand) immediately before testing. After testing, the samples were cleaned with running water followed by an ultrasonic bath for $10 \mathrm{~min}$.

\section{Wear evaluation by roughness measurement}

Surface roughness $(\mathrm{Ra})$ was measured with USB digital surface profile gauge (fig. 2), cut-off -0.25 mm (Elcometer 224/2, Elcometer Instruments, Great Britain) and data were recorded using computer software (Elcomaster 2, Elcometer Instruments). The surface profile needle (radius of $2.5 \mu \mathrm{m}$ ) was positioned perpendicular over each test sample performing five readings in different locations of the sample surface. After the five readings, the mean surface roughness values were obtained.

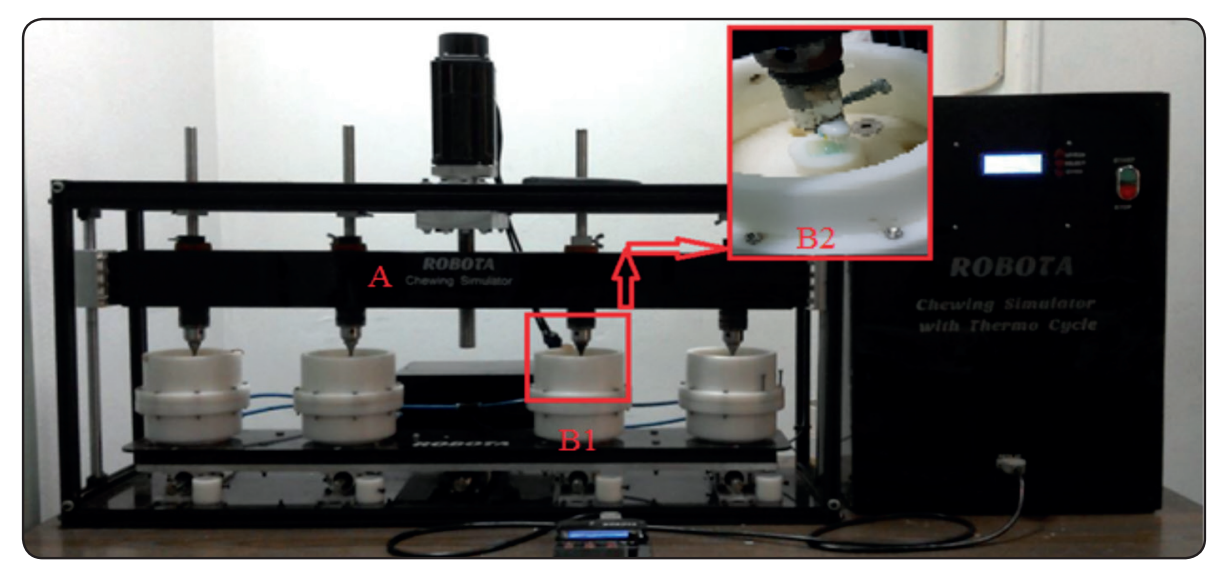

Figure (1) ROBOTA chewing simulator* integrated with thermo-cyclic protocol 


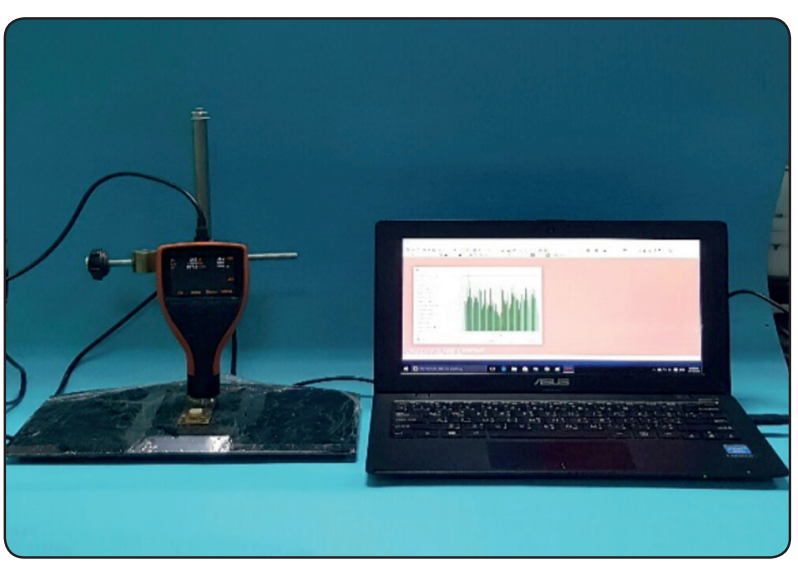

Fig. (2) Elcometer surface profile gauge

To achieve a better reflection on the surface of the samples and qualitative analysis of the wear areas, samples were examined and photographed using the same USB Digital microscope (Scope Capture Digital Microscope, Guangdong, China) at fixed magnification of X 90. Digital microscope images were cropped to $350 \mathrm{x} 400$ pixels using Microsoft office picture manager to specify/standardize area of roughness measurement. This area was chosen on the basis of the dimension of the typical bacteria expected to adhere to restoration surface in vivo. ${ }^{(23)}$ Subsequently, a 3D image of the surface profile of the samples was created using a digital image analysis system WSxM software (Ver 5 develop 4.1, Nanotec, Electronica, SL). ${ }^{(24)}$ The unworn surface served as a reference. With this method, a 3-dimensional geometry of the worn surface was generated.

\section{Statistical analysis}

Data analysis was performed in several steps. Initially, descriptive statistics for each group results. One-way ANOVA followed by pair-wise Tukey's post-hoc tests were performed to detect significance between groups at each wear simulation cycles and between cycles within each material. Two-way ANOVA was done to show effect of each variable (material and wear simulation cycles). Statistical analysis was performed using Graph-Pad InStat statistics software for Windows (www.graphpad. com). $\mathrm{P}$ values $\leq 0.05$ are statistically significant in all tests.

\section{RESULTS}

\section{Roughness changes}

The mean values and standard deviations (SD) for wear measured by roughness average (Ra measured in $\mu \mathrm{m}$ ) recorded on all materials before and after each wear simulation cycles summarized in (table 2) and graphically represented in the column chart (figure 3) and (figure 4).

Baseline; before tooth brushing, there was nosignificant $(\mathrm{p}=0.1599>0.05)$ difference between all materials where (e.max $\geq \mathbf{V}$ enamic $\geq \mathbf{Z r} \geq \mathbf{L}$ ultimate).

After 6 months simulated tooth brushing, there was no-significant $(\mathrm{p}=0.1006>0.05)$ difference between all materials where (e.max $\geq \mathbf{L}$ ultimate $\geq$ $\mathrm{Zr} \geq \mathbf{V}$ enamic).

After 12 months simulated tooth brushing, there was no-significant $(\mathrm{p}=0.9161>0.05)$ difference between all materials where ( $\mathbf{L}$ ultimate $\geq \mathbf{Z r} \geq$ e.max $\geq V$ enamic).

After 18 months simulated tooth brushing, there was significant $(\mathrm{p}=0.002<0.05)$ difference between all materials where $(\mathbf{Z r} \geq \mathbf{V}$ enamic $\geq \mathbf{L}$ ultimate ze.max).

After 24 months simulated tooth brushing, there was no-significant $(\mathrm{p}=0.1556>0.05)$ difference between all materials where $(\mathbf{Z r} \geq \mathbf{e} \cdot \max \geq \mathbf{V}$ enamic $\geq L$ ultimate).

With $\mathbf{Z r}$ material group; there was no-significant $(\mathrm{p}=0.0788>0.05)$ difference between different simulated tooth brushing cycles where $(\mathbf{1 8} \mathbf{~ m} \geq \mathbf{2 4}$ $\mathrm{m} \geq 12 \mathrm{~m} \geq$ baseline $\geq 6 \mathrm{~m}$ )

With $\boldsymbol{V}$ enamic material group; there was nosignificant $(\mathrm{p}=0.3344>0.05)$ difference between 
different simulated tooth brushing cycles where ( $18 \mathrm{~m} \geq$ baseline $\geq 12 \mathrm{~m} \geq 6 \mathrm{~m} \geq 24 \mathrm{~m}$ )

With $L$ ultimate material group; there was nosignificant $(\mathrm{p}=0.3108>0.05)$ difference between different simulated tooth brushing cycles where (18 $\mathrm{m} \geq 12 \mathrm{~m} \geq 6 \mathrm{~m} \geq 24 \mathrm{~m} \geq$ baseline)

With e.max material group; there was significant $(\mathrm{p}=0.008<0.05)$ difference between different simulated tooth brushing cycles where ( $6 \mathrm{~m} \geq$ baseline $\geq 12 \mathrm{~m} \geq 24 \mathrm{~m} \geq 18 \mathrm{~m}$ )
Total effect of material; regardless to toothbrush wear simulation cycles, totally there was nosignificant $(p=0.1379>0.05)$ difference between all materials where $(\mathbf{Z r} \geq \mathbf{e} \cdot \max \geq \mathbf{V}$ enamic $\geq \mathbf{L}$ ultimate).

\section{Total effect of toothbrush wear simulation} cycles; irrespective of material, totally toothbrush wear simulation cycles did not affect roughness significantly $(\mathrm{p}=0.8281>0.05)$ difference between all materials where $(\mathbf{1 8} \mathrm{m} \geq$ baseline $\geq \mathbf{6} \mathrm{m} \geq \mathbf{2 4} \mathrm{m}$ $\geq 12 \mathrm{~m}$ ).

TABLE (2) Wear results (Mean values \pm SD) by roughness change for experimental material groups before and after each toothbrush wear simulation cycles

\begin{tabular}{|c|c|c|c|c|c|c|}
\hline \multirow{2}{*}{\multicolumn{2}{|c|}{ Variables }} & \multicolumn{4}{|c|}{ Experimental material groups } & \multirow{3}{*}{$\begin{array}{c}\text { ANOVA } \\
\text { P value } \\
0.1599 \mathrm{~ns}\end{array}$} \\
\hline & & \multirow{2}{*}{$\begin{array}{c}\text { Zirconia } \\
0.25533 \\
\pm 0.0034\end{array}$} & \multirow{2}{*}{$\begin{array}{c}\text { V enamic } \\
0.25652 \\
\pm 0.0022 \\
\end{array}$} & \multirow{2}{*}{$\begin{array}{c}\text { L ultimate } \\
0.25345 \\
\pm 0.0014 \\
\end{array}$} & \multirow{2}{*}{$\begin{array}{c}\text { e.max } \\
0.2571 \\
\pm 0.0031 \\
\end{array}$} & \\
\hline \multirow{5}{*}{$\begin{array}{l}\text { Toothbrush wear } \\
\text { simulation cycles }\end{array}$} & Baseline & & & & & \\
\hline & 6 months & $\begin{array}{r}0.2545 \\
\pm 0.0033\end{array}$ & $\begin{array}{l}0.25438 \\
\pm 0.0012\end{array}$ & $\begin{array}{l}0.25567 \\
\pm 0.0008\end{array}$ & $\begin{array}{l}0.25735 \\
\pm 0.0012\end{array}$ & $0.1006 \mathrm{~ns}$ \\
\hline & 12 months & $\begin{array}{l}0.25562 \\
\pm 0.0028\end{array}$ & $\begin{array}{l}0.25473 \\
\pm 0.0022\end{array}$ & $\begin{array}{l}0.25583 \\
\pm 0.0024\end{array}$ & $\begin{array}{l}0.25523 \\
\pm 0.0032\end{array}$ & $0.9161 \mathrm{~ns}$ \\
\hline & 18 months & $\begin{array}{c}0.2590 \\
\pm 0.0015\end{array}$ & $\begin{array}{l}0.25692 \\
\pm 0.0011\end{array}$ & $\begin{array}{l}0.25583 \\
\pm 0.0029\end{array}$ & $\begin{array}{l}0.25325 \\
\pm 0.0025\end{array}$ & $0.002 *$ \\
\hline & 24 months & $\begin{array}{l}0.25898 \\
\pm 0.0035\end{array}$ & $\begin{array}{l}0.25413 \\
\pm 0.0049\end{array}$ & $\begin{array}{l}0.25403 \\
\pm 0.0028\end{array}$ & $\begin{array}{l}0.25428 \\
\pm 0.0029\end{array}$ & $0.1556 \mathrm{~ns}$ \\
\hline ANOVA & P value & $0.0788 \mathrm{~ns}$ & $0.3344 \mathrm{~ns}$ & $0.3108 \mathrm{~ns}$ & $0.008 *$ & \\
\hline
\end{tabular}

*; significant $(p<0.05)$

ns; non-significant ( $p>0.05)$

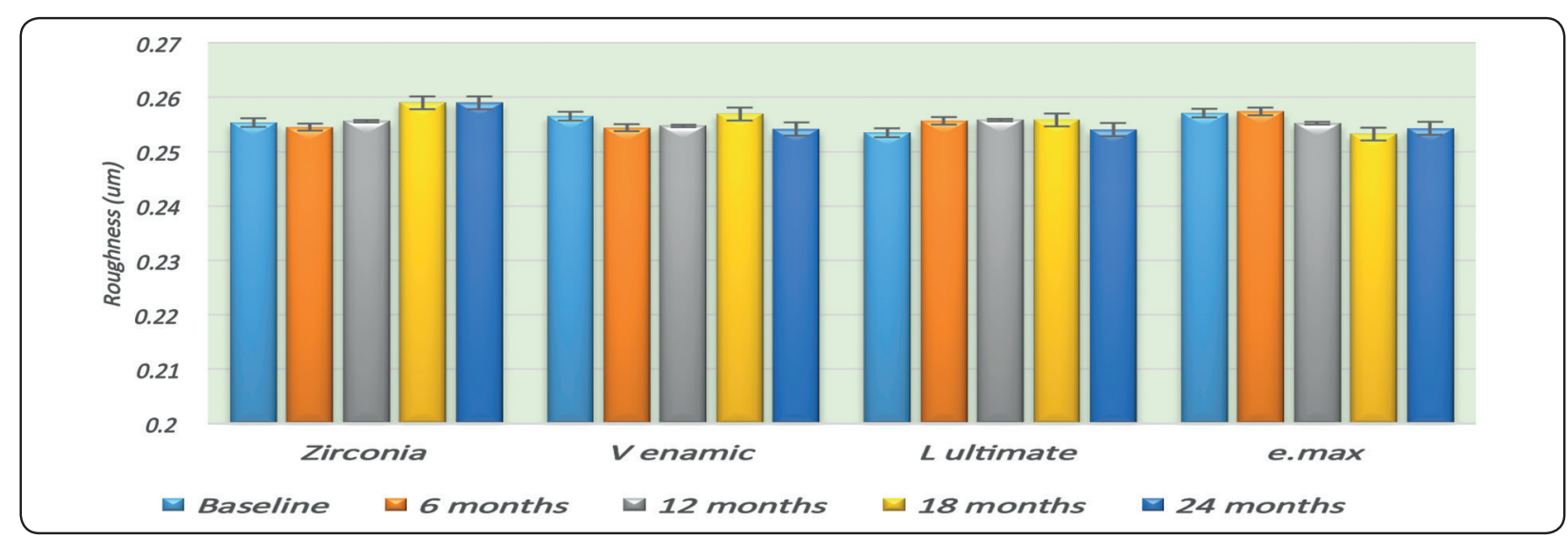

Fig. (3) Column chart of the mean values of surface roughness of ceramic samples 


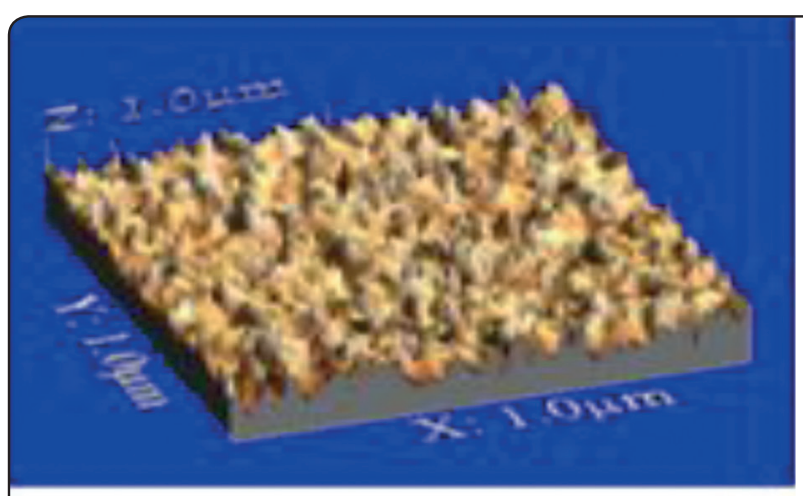

Before tooth brush wear simulation test

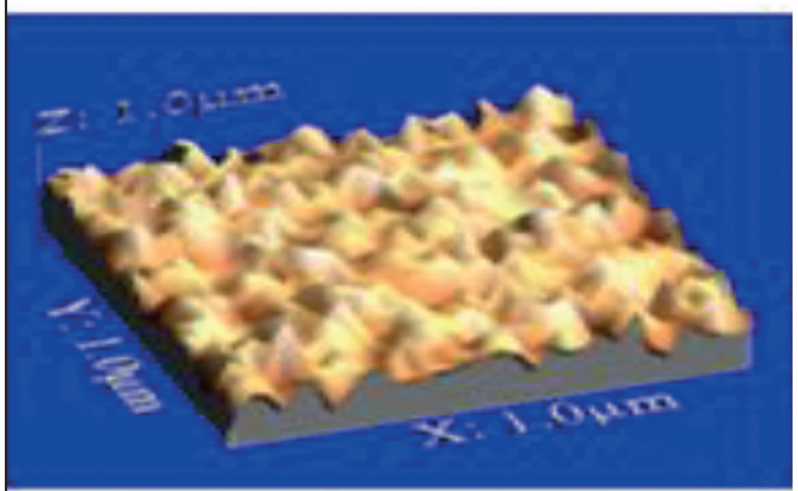

After 6 months tooth brush wear simulation test

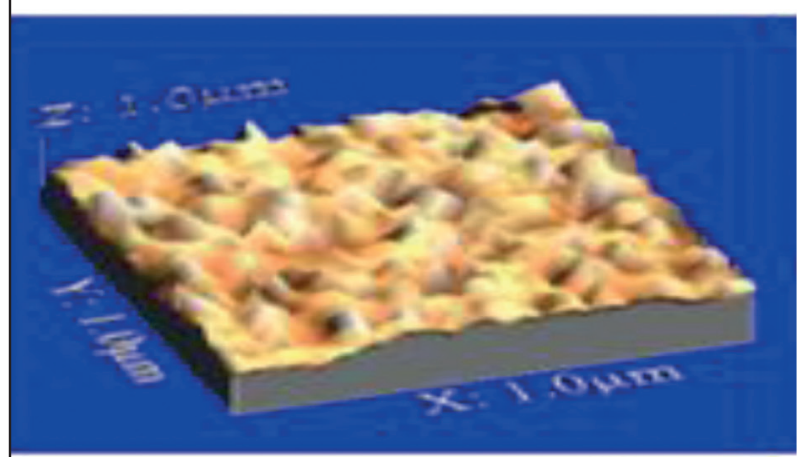

After 24 months tooth brush wear simulation test

\section{DISCUSSION}

Surface roughness of dental restorations may result from long term dentifrices usage that might cause several problems such as surface stains, attraction of dental plaque \& wear of occluding teeth. Various kinds of ceramic blocks are available in the market recently, most of these materials exhibited higher hardness and higher resistant to both wear and staining \& their low susceptibility to fracture. ${ }^{(25,26)}$ Little data is available about the

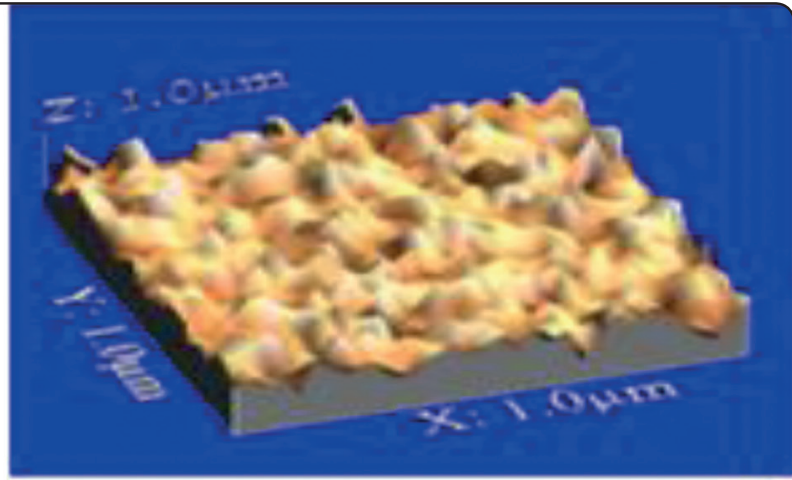

After 12 months tooth brush wear simulation test

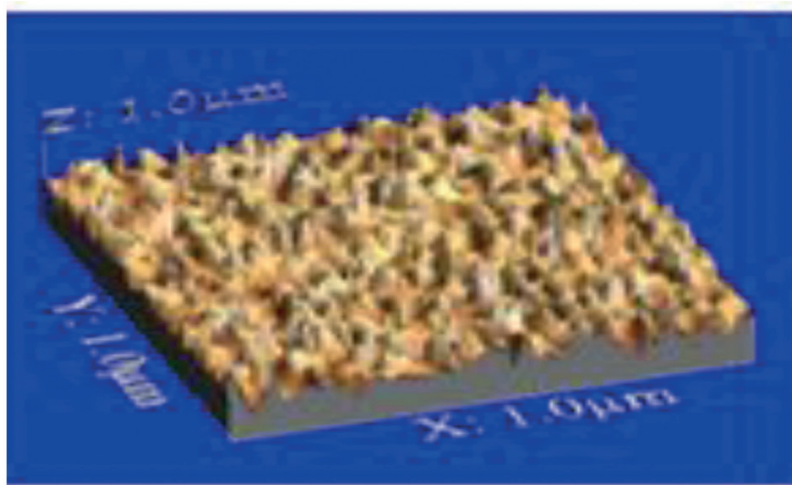

After 18 months tooth brush wear simulation test

Fig. (4) Representative 3D image of samples after toothbrush wear simulation test

effect of tooth brushing/dentifrices combination on the surface properties of current dental materials, including ceramics. Some studies were performed on ceramic blocks reported higher failure of restorations fabricated from these blocks and attributed this failure to their surface roughness and increased wear pattern. ${ }^{26,27)}$

Brushing effects on the surface properties of dental materials were evaluated in the study using simulated tooth brushing abrasion test, which is 
considered a typical model in the literature. ${ }^{(28,29)}$ The load of brushing application in the present study was (300 g) that is near to the range of clinical application and consistent with other studies (200 g to $350 \mathrm{~g}){ }^{(30-32)}$

The discussion regarding how much $\mathrm{Ra}$ values that considered clinically acceptable are controversial opinions in the literature, however, $\mathrm{Ra}$ values after brushing with conventional dentifrice in the present study is agreed with another study \& were clinically acceptable where it presents within the Ra range from 0.25 um to $0.5 \mathrm{um}$, which is undetectable clinically by the tongue. ${ }^{(33)}$

Because surface roughness on the order of $0.3 \mathrm{~mm}$ can be detected clinically by the tip of the patient's tongue and might cause discomfort for the patient. ${ }^{(33)}$ The Ra values obtained in this study disagree and differ from the values obtained in other studies in which the Ra values ranged from 0.18 to 0.98 um. ${ }^{(28,34)}$

In the present study different kinds of ceramic blocks (Zirconia, e.max, Vita enamic \& Lava ultimate) were used to include different classification of ceramics as possible. Roughness values $(\mathrm{Ra})$ is different in all kinds of ceramics tested in the study resulting different wear pattern of each type of ceramics, that is closely influenced by microstructure and physical characteristics of ceramic type, specifically hardness, flexural strength and fracture toughness. ${ }^{(35)}$

Another influencing factor is the abrasiveness of the slurry formed by the dentifrice during brushing $\&$ physical characteristics of the abrasive particles, namely shape, size, acuteness, and hardness. Thus, the abrasive type, the chemical reaction between detergents and abrasives, the $\mathrm{pH}$, and the rheologic properties of the final slurry can change surfaces in different ways. ${ }^{(36-38)}$ Another probable explanation is ceramic materials with small grain size in matrix such as zirconia enable it to be more resistant to wear action than e.max \& other types of ceramics that have more large grain size particles $(.04 \mathrm{um}$ of zirconia \& 2 um of lithium disilicated tested specimens). ${ }^{(14)}$

Even with the higher hardness zirconia blocks, the results found in this study showed that all zirconia specimens brushed with dentifrice subjected to more roughness and surface topography that is agree with some investigators. ${ }^{(39-41)}$ That is may be attributed to its low temperature degradation that occurs in moist environments. ${ }^{(40,41)}$ Another explanation is probably related to the influence of $\mathrm{pH}$ variations and the concentration of fluoride on the zirconia's susceptibility to degradation. ${ }^{(42,43)}$ While a neutral $\mathrm{pH}$ does not change the microstructural appearance of zirconia surfaces, but alkaline and acid pHs may corrode the surface of the material. ${ }^{(43)}$ Low temperature degradation is responsible for grain push-out, ${ }^{(44,45)}$ increased surface roughening \& wear. ${ }^{(44,45)}$ On the other hand different results, such as unchanged roughness after brushing with conventional dentifrice and roughened ceramic surfaces after brushing with whitening dentifrice, have been published in other studies. ${ }^{(28,48)}$

Although, homogenous and smooth wear patterns can be seen for lithium disilicate (e.max blocks) may be considerably attributed to smaller grain size of lithium disilicate crystals when compared with leucite crystals of glass based ceramics. ${ }^{(49,50)}$ The null hypotheses of the study is partially rejected because surface roughness and wear of dental restorations occurred but with no significant differences.

One limitation of this study is the only single polishing protocol using diamond instrument for all ceramic types. Diamond particle sizes and their distribution may affect polishing surfaces of each type of ceramic. More over one type of tooth paste used in the present study. During intraoral tooth brushing, tooth paste is diluted \& buffered by action of salivary flow, their ions \& protein content may diminish roughening action of brushing, it may be performed in other future studies, also several types of abrasives and tooth paste can be tested in the future. 
Conclusion; Brushing of ceramic materials with conventional dentifrices non-significantly increased surface roughness, where results of surface roughness present within the clinically acceptable range, not insult the patient intraorally.

\section{CONCLUSIONS}

1- Brushing of ceramic materials used in this study (Prettau, Vita enamic, Lava ultimate, and IPS e max CAD) with conventional dentifrices not significantly increase surface roughness.

2- Surface roughness increased consequently from zirconia $\geq \mathrm{e} \max \mathrm{CAD} \geq$ Vita enamic $\geq$ lava ultimate.

3- Surface roughness after 18 months was prominent than other times

4- Surface roughness of all used materials was within the clinically acceptable range.

\section{REFERENCES}

1. Conforti NJ, Chaves ES, Liebman J, Bowman JP, Warren PR, Cugini M. A comparative 3-month clinical investigation of the safety and efficacy of a battery-operated and a rechargeable oscillating-rotating power toothbrush. Am J Denl. 2001;14: 59-62.

2. Putt MS, Milleman JL, Davidson JR, Kleber CJ, Cugini M. A split-mouth comparison of a three-dimensionalaction electric toothbrush and a high-frequency electric toothbrush for reducing plaque and gingivitis. J Int Acad Periodontol. 2001. Oct; 3(4): 95-103.

3. Hefti AF, Stone C. Power toothbrushes, gender, and dentin hypersensitivity. Clin Oral Invest 2000;4: 91-97.

4. Hunter ML, Addy M, Pickles MJ \& Joiner A. The role of toothpastes and toothbrushes in the etiology of tooth wear. International Dental Journal 2002; 5/02:399-405.

5. Addy M. \& Hunter ML. Can tooth brushing damage your health? Effects on oral and dental tissues. International Dental Journal (2003) 53, 177-86.

6. Sorensen J, Nguyen H. Evaluation of toothbrush-induced dentin substrate wear using an in vitro ridged-configuration model. Am J Dent. 2002;15: 26B-32B.
7. Joiner A. Whitening toothpastes: a review of the literature. J Dent 2010;38: 17-24.

8. Khamverdi Z, Kasraie S, Rezaei-Soufi L, Jebeli S. Comparison of the effects of two whitening toothpastes on microhardness of the enamel and a microhybrid composite resin: an in vitro study. J Dent (Tehran) 2010;7: 139-45.

9. Baig MR, Tan KB-C, Nicholls JI. Evaluation of the marginal fit of a zirconia ceramic computer-aided machined (CAM) crown system. J Prosthet Dent. 2010;104:216-27.

10. Kim HK, Kim SH, Lee JB, Ha SR. Effects of surface treatments on the translucency, opalescence, and surface texture of dental monolithic zirconia ceramics. J Prosthet Dent 2016;115:773-79.

11. Coachmanand C \& Paravina RD. Digitally enhanced esthetic dentistry-From treatment planning to quality control. J Esthet Restor Dent 2016;28:S3-S4.

12. Kelly JR, Benetti P. Ceramic materials in dentistry: historical evolution and current practice. Aust Dent J 2011;56(Suppl 1):84-96.

13. Bachhav VC, Aras MA. Zirconia-based fixed partial dentures: a clinical review. Quintessence Int. 2011;42:173-82.

14. Amer R, Kürklü D, Johnston W. Effect of simulated mastication on the surface roughness of three ceramic systems. J Prosthet Dent 2015;114:260-65.

15. Vagkopoulou T, Koutayas SO, Koidis P, Strub JR. Zirconia in dentistry: Part1. Discovering the nature of an upcoming bioceramic. Eur J Esthet Dent 2009;4: 130-51.

16. Dirxen C, Blunck U and Preissner S. Clinical Performance of a New Biomimetic Double Network Material. The Open Dentistry Journal 2013; 7: 118-22.

17. Coldea A, Swain MV, Thiel N. Mechanical properties of polymer infiltrated-ceramic-network materials: Official publication of the Academy of Dental Materials. Dent Mater 2013; 29: 419-26.

18. Albashaireh ZSM, Ghazal M, Kern M. Two-body wear of different ceramic materials opposed to zirconia ceramic. J Prosthet Dent 2010;104:105-13.

19. Jung YS, Lee JW, Choi YJ et al. A study on the in-vitro wear of the natural tooth structure by opposing zirconia or dental porcelain. J Adv Prosthodont 2010;2:111-15.

20. Ghazal M, Kern M. The influence of antagonistic surface roughness on the wear of human enamel and nanofilled composite resin artificial teeth. J Prosthet Dent 2009;101: 342-49. 
21. Wang L, Garcia FC, Amarante de Araujo P, Franco EB, Mondelli RF. Wear resistance of packable resin composites after simulated tooth brushing test. J Esthet Restor Dent 2004;16:303-14.

22. Cilli R, de Mattos MC, Honorio HM, Rios D, de Araujo PA, Prakki A. The role of surface sealants in the roughness of composites after a simulated tooth brushing test. J Dent 2009;37:970-77.

23. Giacomelli L, Derchi G, Frustaci A, Bruno O, Covani U, Barone A, De Santis D and Chiappelli F. Surface Roughness of Commercial Composites after Different Polishing Protocols: An Analysis with Atomic Force Microscopy. The Open Dentistry Journal 2010;4:191-94.

24. Horcas I, Fernandez R, Gomez JM, Colchero J, GomezHerrero J, and Baro AM. Review of Scientific Instruments 2007;78: 013705.

25. Kois DE, Isvilanonda V, Chaiyabutr, Kois JC. Evaluation of fracture resistance and failure risks of posterior partial coverage restorations. J Esthet Restor Dent 2013; 25:110-22.

26. Ruse ND, Sadoun MJ. Resin composite blocks for dental CAD/CAM applications. J Dent Res 2014;93:1232-34.

27. Vanoorbeek S, Vandamme K, Lijnen I, Naert I. Computeraided designed/computer assisted manufactured composite resin versus ceramic single-tooth restorations: a 3-year clinical study. Int J Prosthodont 2010;23:223-30.

28. Candido LM, Fais LMG, Reis JMSN, Pinelli LAP. Surface roughness and hardness of yttria stabilized zirconia (Y-TZP) after 10 years of simulated brushing. Rev Odontol UNESP 2014;43:379-83.

29. Monteiro B, Spohr AM. Surface roughness of composite resins after simulated toothbrushing with different dentifrices. J Int Oral Health 2015;7:1-5.

30. Neme AL, Frazier KB, Roeder LB, Debner TL. Effect of prophylactic polishing protocols on the surface roughness of esthetic restorative materials. Oper Dent 2002;27:50-58.

31. dos Santos PH, Consani S, Correr Sobrinhol L, Coelho Sinhoreti MA. Effect of surface penetrating sealant on roughness of posterior composite resins. Am J Dent 2003;16:197-201.

32. Teixeira EC, Thompson JL, Piascik JR, Thompson JY. In vitro tooth brush-dentifrice abrasion of two restorative composites. J Esthet Restor Dent 2005;17:172-80.
33. Jones CS, Billington RW, Pearson GJ. The in vivo perception of roughness of restorations. Br Dent J 2004; 196:42-45.

34. Luangruangrong P, Cook NB, Sabrah AH, Hara AT, Bottino $\mathrm{MC}$. Influence of full-contour zirconia surface roughness on wear of glass ceramics. J Prosthodont 2014;23:198-205.

35. Heintze SD, Cavalleri A, Forjanic M, et al: Wear of ceramic and antagonist- a systematic evaluation of influencing factors in vitro. Dent Mater 2008;24:433-49.

36. Turssi CP, Purquerio BM, Serra MC. Wear of dental resin composites: insights into underlying processes and assessment methodsda review. J Biomed Mater Res B Appl Biomater 2003;65:280-85.

37. Moore C, Addy M. Wear of dentine in vitro by toothpaste abrasives and detergents alone and combined. J Clin Periodontol 2005;32:1242-46.

38. Johannsen G, Tellefsen G, Johannsen A, Liljeborg A. The importance of measuring toothpaste abrasivity in both a quantitative and qualitative way. Acta Odontol Scand 2013;71:508-17.

39. Pinelli LA, Olbera AC, Candido LM, Miotto LN, Antonio SG, DDSc, and Grassi Fais LM,. Effects of whitening dentifrice on yttria-stabilized tetragonal zirconia polycrystal surfaces after simulating brushing. (J Prosthet Dent 2016 Article in press).

40. Cattani-Lorente M, Scherrer SS, Ammann P, Jobin M, Wiskott HW. Low temperature degradation of a Y-TZP dental ceramic. Acta Biomater 2011;7: 858-65.

41. Kawai Y, Uo M, Wang YM, Kono S, Ohnuki S, Watari F. Phase transformation of zirconia ceramics by hydrothermal degradation. Dent Mater J 2011;30:286-92.

42. Mukaeda LE, Taguchi SP, Robin A, Izario HJ, Salazar RFS, Santos C. Degradation of Y2O3-stabilized $\mathrm{ZrO} 2$ ceramics in artificial saliva: ICP analysis of dissolved Y3+ and Zr4+ ions. Mater Sci Forum 2012;727-8:1136-41.

43. Turp V, Tuncelli B, Sen D, Goller G. Evaluation of hardness and fracture toughness, coupled with microstructural analysis, of zirconia ceramics stored in environments with different pH values. Dent Mater J 2012;31:891-902.

44. Deville S, Gremillard L, Chevalier J, et al: A critical comparison of methods for the determination of aging sensitivity in biomedical grade yttria-stabilized zirconia. J Biomed Mater Res Part B: Appl Biomater 2005;72:239-45. 
45. Chevalier J: What future for zirconia as a biomaterial? Biomaterials 2006;27:535-43

46. Hernigou P, Bahrami T. Zirconia and alumina ceramics in comparison with stainless-steel heads. Polyethylene wear after a minimum ten-year follow-up. J Bone Joint Surg Br 2003;85:504-09

47. Santos EM, Vohra S, Catledge SA, et al: Examination of surface and material properties of explanted zirconia femoral heads. J Arthroplast 2004;19(Suppl 2):30-34
48. Azevedo SM, Kantorski KZ, Valandro LF, Bottino MA, Pavanelli CA. Effect of brushing with conventional versus whitening dentifrices on surface roughness and biofilm formation of dental ceramics. Gen Dent 2012;60(37): 123-30.

49. Denry I, Holloway JA: Ceramics for dental applications: a review. Materials 2010;3:351-368

50. Imai Y, Suzuki S, Fukushima S: Enamel wear of modified porcelains. Am J Dent 2000;13:315-23. 